\title{
DE SENHORES A ESCRAVOS DAS IMAGENS: O HOMEM, A FOTOGRAFIA DIGITAL E O DOMÍNIO DAS IMAGENS TÉCNICAS
}

\author{
Gilucci Augusto Oliveira \\ PPGDCI / UEFS - Discente no programa de pós graduação em Desenho, Cultura e \\ Interatividade. \\ gilucciaugusto@hotmail.com
}

\begin{abstract}
Resumo
O texto, discute a fotografia digital enquanto imagem técnica, alguns de seus aspectos e usos na atual sociedade e para tanto, primeiramente, traça-se um breve panorama do termo imagem, da pré-história, passando pelos mitos de Narcíso e de Sísifo, até chegar ao advento da fotografia no século XIX, para logo depois, também abordar algumas das ideias de Vilém Flusser e sua Filosofia da Caixa Preta, que possibilitará uma discussão a respeito da fotografia digital e suas influências, de forma que possamos refletir sobre um possivel "antropocentrismo imagético".
\end{abstract}

Palavras-chave: imagem, fotografia, antropocentrismo imagético, Vilém Flusser

\section{Resumen}

El texto, piensa la fotografía digital como imagen técnica, algunos de sus aspectos y usos en la actual sociedad y para tanto, primero, se traza un breve panorama del término imagen, de la prehistoria, pasando por los mitos de Narcismo y de Sísifo, hasta llegar al advenimiento de la fotografía en el siglo XIX, para luego, también abordar algunas de las ideas de Vilém Flusser y su Filosofía de la Caja Negra, que posibilitará una discusión acerca de la fotografía digital y sus influencias, de forma que podamos reflexionar sobre un posible "Antropocentrismo imagético".

Palabras clave: imagen, fotografía, antropocentrismo imagético, Vilém Flusser

\section{Introdução}

Este artigo, busca em um primeiro momento fazer um breve panorama a respeito da imagem e suas origens, com o intuito de se construir um caminho que possibilite abordar a fotografia, enquanto imagem técnica e tecnológica, e assim refletir sobre a mesma, seus usos e influências, numa possível sociedade da informação ou pós- 
industrial. Com isso, objetiva-se aqui, contribuir com reflexões e discussões que nos ajudem a entender ou mesmo ver por outras perspectivas, a atual fotografia digital.

Nesse contexto, o presente trabalho nasceu de minhas primeiras reflexões, estudos e inquietações, tanto acadêmicas, quanto artísticas, a partir do meu recente ingresso como discente no Programa de Pós-graduação em Desenho, Cultura e Interatividade, da Universidade Estadual de Feira de Santana (PPGDCI-UEFS), na Bahia. Assim, coloquei-me a pensar, partindo dos vários aspectos que rodeiam minha produção fotográfica, até chegar à fotografia digital, em um contexto mais geral, para além de seus usos nas "artes", e como parecemos nos relacionar e sermos influenciados pela mesma, no atual contexto tecnológico de nossa sociedade. De modo que, na tentativa de unir o meu fazer artístico com minha produção acadêmica e científica, ilustro o texto com duas fotografias digitais autorais, logo, na imagem da figura 1 veremos uma fotografia produzida com a técnica de light paint ${ }^{1}$, a partir de uma "escultura" construída com parte de um manequim feminino, uma cabeça de isopor presa dentro de uma gaiola, ornamentada por flores (aqui não pretendo fazer uma leitura de meu próprio trabalho e sim descrevê-lo de forma objetiva, a fim de contextualizá-lo). Já na imagem da figura 2, onde também utilizo a técnica de light paint, com uma exposição de 30 segundos, ilustro com um autorretrato a parte do texto que trato dos mitos de Narciso e de Sísifo, de forma análoga ao contexto da produção imagética da atual sociedade, que como dito acima, é o principal objeto de estudo do texto.

\section{Homem: deus-imagem}

Criou Deus o homem à sua imagem, à imagem de Deus o criou; homem e mulher os criou. Gênesis 1:27

No Ocidente, de forma simbólica e devido a visão religiosa judaico-cristã, arraigada na cultura ocidental, parece estar convencionada a crença de que somos não apenas

\footnotetext{
${ }^{1}$ Técnica fotográfica que se dá, a partir de uma longa exposição, onde a cena ou o objeto fotografado, será iluminado por luzes produzidas por lanternas, velas e afins, de modo que, o fotógrafo ganha liberdade ao poder "modelar" e dar forma a luz criando letras, palavras, formas abstratas ou apenas iluminar de maneira mais minuciosa e criar atmosferas e texturas diferentes, em ambientes totalmente escuros. Graças ao obturador aberto por tempo demorado, que registra em uma imagem estática, o movimento da luz propriamente, ou do reflexo da mesma, através dos objetos.
} 
filhos de Deus, mas, fomos criados a imagem e semelhança do mesmo. "Do mito da caverna à Bíblia, aprendemos que somos nós próprios imagens, seres que se assemelham ao Belo, ao Bem e ao Sagrado" (JOLY, 2007, p. 16). Neste sentido, fundamenta-se também, no relato bíblico (Gênesis, 1:27), a ideia cristã do homem enquanto centelha divina e sua filiação com a divindade criadora, o que parece, habilitar-lhe e impulsionar a criar também, coisas outras à sua própria imagem e semelhança. Porém, os relatos a respeito das primeiras criações imagéticas humanas, antecedem as filosofias e ideias gregas e cristãs, assim, temos conhecimento que o homem já produzia imagens desde o paleolítico, a exemplo das Sepulturas de Aurignaciano datadas de 30.000 a.C., e as figuras desenhadas nas cavernas de Lascaux, no sudeste da França, 15.000 a.C. (DEBRAY, 1994). Contudo, no que tange a origem do termo "imagem", veremos que,

\begin{abstract}
A palavra imagem teve sua origem no latim imago, que no mundo antigo significava máscara de cera utilizada nos rituais de enterramento para reproduzir o rosto dos mortos. Ela nasceu, assim, da morte para prolongar a vida e apresentou, com isso, as noções de duplo e de memória. A imagem tinha o papel de recompor o homem, cujo corpo se decompõe pela morte. Desse modo ela teve um caráter mágico ao proteger os vivos da visão do corpo em putrefação e de libertá-los de seus temores diante da morte. Logo, a imagem emergiu tendo a função de tornar presente o ausente e dar continuidade à existência terrena (KERN, 2006, p. 15).
\end{abstract}

Portanto, este sentido de imagem, que também pode ser a alma ou o espectro do falecido, tanto para Debray (1994), quanto para Joly (2007), está conectado a toda a história da arte e não apenas à morte e aos ritos funerários. Pode-se dizer que o desejo humano de vencer a morte, prolongar a vida, ou tornar-se semideuses, lançounos cada vez mais em várias dimensões imagéticas. Na Grécia Antiga, mais especificamente os ceramistas atenienses, quando para representar o nascimento da imagem, se utilizavam da miniatura de um guerreiro, saindo da tumba de um guerreiro morto em combate, nesse contexto, segundo Debray (1994), a imagem testemunharia o triunfo da vida sobre a morte. O mundo imagético parecia ser tão importante, que os gregos antigos, quando em referência à morte, usavam o termo "sua última mirada", ao invés de "seu último suspiro", como nós costumamos falar nos dias atuais, logo, para o grego antigo, viver era ver e não respirar, e morrer era perder a visão, ficar cego (DEBRAY, 1994). São várias as acepções de imagem, e devido a ambiguidade e polissemia do termo, se faz necessário aqui oferecer algumas explicações ou delimitações para a palavra "imagem". 


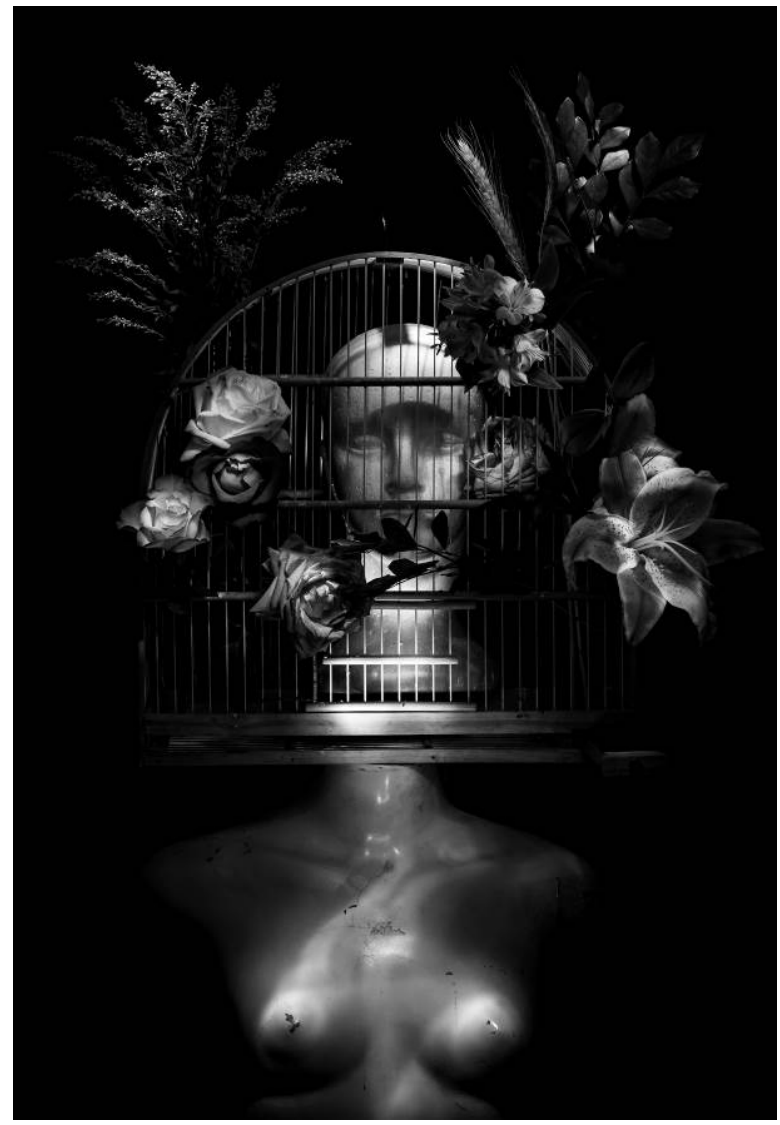

Figura 1- Deus - humano, da Série Corpus et Spiritus da autoria de Gilucci Augusto. Fotografia. 2016.

Fonte: Coleção particular do autor.

Segundo Santaella (2012), mesmo restringindo o termo "imagem", ao campo da visualidade, teremos pelo menos três ou cinco domínios principais para "imagem". Assim sendo, e, ainda segundo Santaella (2012), podemos falar de imagem sob o domínio das imagens mentais, imaginadas e oníricas; domínio das imagens diretamente perceptíveis (imagens que apreendemos diretamente da realidade e do mundo visível); domínio das imagens como representações visuais, domínio onde se situam o desenho, as gravuras, a fotografia, a pintura, imagens televisivas e cinematográficas, holografias e imagens computacionais. Há ainda o domínio das imagens verbais, do qual fazem parte as metáforas, descrições e outros meios linguísticos; por último, o domínio das imagens ópticas, tais como projeções e espelhos. Sabendo disso, cabe ressaltar que, nosso objeto principal de pesquisa ${ }^{2}$ será

\footnotetext{
${ }^{2}$ Atualmente, me encontro realizando os ajustes finais do meu projeto de pesquisa, que objetiva investigar as marisqueiras da região quilombola de Santiago do Iguape, situada em Cachoeira-BA, para tanto, pretendo utilizar como suporte imagético a fotografia documental (digital) em preto e branco, produzida a partir de minha interação com os atores sociais da mesma localidade. O projeto pretende ser finalizado em abril do ano de 2019 e conta com a orientação do Prof. Dr. Edson Dias Ferreira (PPGDCI-UEFS).
} 
a imagem técnica, mais especificamente, a fotografia digital, e a mesma se encontra dentro do domínio da imagem enquanto representação visual e suas várias modalidades, desde imagens em si mesmas (formas puras, abstratas e coloridas), imagens figurativas e imagens simbólicas. Como imagens simbólicas, por enquanto, podemos compreender imagens que necessitam da ajuda do código de uma convenção cultural, para que possamos entender o significado da própria imagem e de seus elementos (SANTAELLA, 2015).

\section{De Narciso a Sísifo}

No mito de Narciso, segundo a versão de Ovídeo (UBINHA e CASSORLA, 2003), Narciso, apaixonado pela própria imagem, sem se dar conta de que se tratava do seu reflexo na água, definha na margem de um lago, sem comer nem dormir, e morre tentando segurar em seus braços, o reflexo da luz de si mesmo, seu objeto de obsessão e paixão, seu "eu" imagético. Narkissos, o nome da flor que nasce no local de sua morte "vem de narké, entorpecimento, raiz etimológica de narcótico" (UBINHA e CASSORLA, 2003, p. 77). Das palavras de Alberti (1999), quando ao falar de uma possível gênese da pintura, e fazer uma breve analogia ao mito de Narciso, sugerindo o mesmo, como inventor da pintura, percebe-se o antigo anseio humano de fixar imagens, nesse caso, a própria imagem pictórica, a fim de se sobrepor à morte, eternizando o efêmero. Assim, também afirma Belting (2014, p. 13), ao dizer que, "as artes nasceram a sombra da morte. As imagens e a produção imaginal foram uma tentativa de superar o trauma da morte".

Assim como no mito de Narciso, “ depois de já possuirmos um mundo virtual da aparência perfeita, que a tecnologia nos coloca dentro de casa" (BELTING, 2014, p. 03), nos confundimos, passamos a cultuar nosso próprio eidôlon (DEBRAY, 1994), espectro e sombra, de tal forma, que nossas imagens refletidas nas telas de computadores, celulares e em tantas redes sociais tais como Facebook e Instagram, podem facilmente, também, ilustrar de forma análoga, o mito de Sísifo. Porém, nesse contexto, ao invés de carregarmos uma pedra, rumo ao topo da montanha, em um ritual de iteração eterna, os deuses, parecem haver nos castigado e condenado a "contrapor ao mundo um mundo imaginal próprio, para nele se pretender habitar" (BELTING, 2014 p. 21), nesse sentido, podemos dialogar sobre as possibilidades de mundos virtuais, logo a frente, quando trataremos da imagem técnica e suas possibilidades, advindas da tecnologia. Assim, igualmente ao ritual de iteração de Sísifo, estamos condenados a lançar, de forma contínua e repetida, imagens em um 
mundo existente (BELTING, 2014). De maneira tal, nada poética e bastante vertiginosa, que a produção massiva de imagens, nos dias atuais, parece anunciar a nossa morte em um mundo qualquer, físico/material e, ao contrário de Sísifo, que em Hades permaneceria eternamente, renascemos em outro mundo, o mundo virtual, mas nesse contexto, não parecemos ressurgir na forma de uma bela flor, assim como Narciso na margem do lago. Renascemos apenas entorpecidos, idólatras, como quem houvera inalado o aroma sedutor de narkissos, flor que deu lugar a imagem humanoobjetiva e ao próprio eidôlon de Narciso, seu amor, sua paixão em forma de luz. De modo que, de deus criador de imagens, parecemos passar a escravos da entidade imagética e sua fome por mais imagens de imagens. "A imortalidade das imagens, que inicialmente nos salvou da morte, eternizando-nos, pode, agora, nos oprimir" (ROCHA, 2013, p.83).

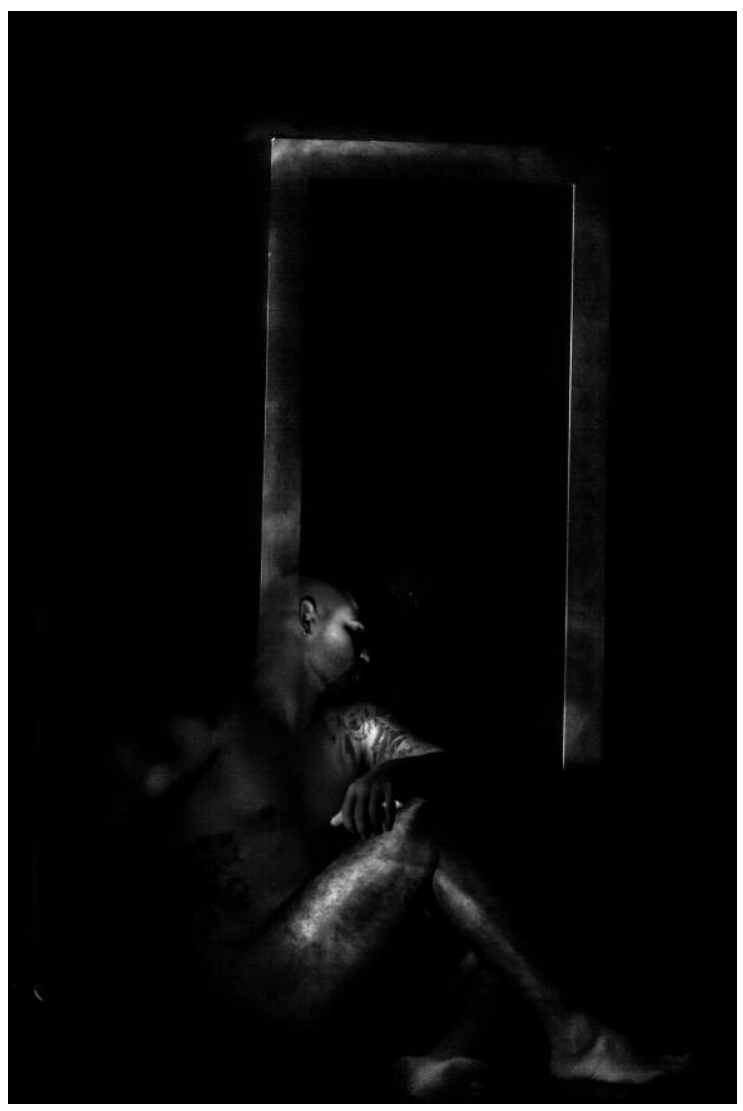

Figura $2^{3}$ - Auto-retrato, homem ao espelho, da Série Corpus et Spiritus da autoria de Gilucci Augusto. Fotografia. 2016. Fonte: Coleção particular do autor.

\footnotetext{
${ }^{3}$ A ideia de produzir um autorretrato através de uma longa exposição, também se contrapõe de certo modo, a noção de instantaneidade, tão presente na fotografia digital atual, por trinta segundos, enquanto ilumino meu próprio corpo com uma lanterna, forço em mim mesmo uma outra consciência temporal fotográfica, preciso pensar quais partes desejo que seja mais ou melhor iluminada, se quero uma imagem borrada, com movimento ou apenas estática, de algum modo exagero no ato especular, não apenas objetivamente.
} 
Assim, vale lembrar o profético Vilém Flusser (2011) e sua Filosofia da Caixa Preta, que em meados da década de 80 , já se antecipava em prever, algumas das facetas de nossa atual sociedade, no que tange a produção e o uso de imagens:

\begin{abstract}
Imagens são mediações entre homem e mundo. O homem "existe", isto é, o mundo não the é acessível imediatamente. Imagens têm o propósito de lhe representar o mundo. Mas, ao fazê-lo, entrepõem-se entre mundo e homem. Seu propósito é serem mapas do mundo, mas passam a ser biombos. O homem, ao invés de se servir das imagens em função do mundo, passa a viver em função de imagens. Não mais decifra as cenas da imagem como significados do mundo, mas o próprio mundo vai sendo vivenciado como conjunto de cenas. Tal inversão da função das imagens é idolatria. Para o idólatra - o homem que vive magicamente -, a realidade reflete imagens. Podemos observar, hoje, de que forma se processa a magicização da vida: as imagens técnicas, atualmente onipresentes, ilustram a inversão da função imaginística e remagicizam a vida. (FLUSSER, 2011 p. 17)
\end{abstract}

Aqui, Flusser (2011), além de reforçar as ideias discorridas acima, também trata de maneira global, a respeito da aparição da imagem técnica ${ }^{4}$ e suas influências, tema que voltaremos a discutir mais adiante, mas antes se faz necessário situarmos a fotografia e sua gênese, para logo depois, tratarmos da fotografia digital.

\title{
FOTOGRAFIA: a invenção e o domínio das imagens técnicas
}

$\mathrm{Na}$ forma do Daguerreótipo ${ }^{5}$, a fotografia, foi apresentada ao mundo, oficialmente na França em agosto de 1839, como resultado de pesquisas, experimentações e o "entroncamento de duas séries de conhecimentos e de dispositivos seculares: de um lado, a câmara escura, o óptico; do outro, a sensibilidade à luz de certas substâncias" (ROUILLÉ, 2009, p.33). Assim, Rouillé (2009), relaciona, a invenção da fotografia, à dinâmica de uma sociedade industrial que emergia, buscando atender necessidades de imagens e representações dessa mesma sociedade, de tal jeito que, também e

\footnotetext{
4 "Trata-se de imagem produzida por aparelhos. Aparelhos são produtos da técnica que, por sua vez, é texto científico aplicado. Imagens técnicas são, portanto, produtos indiretos de textos - o que lhes confere posição histótica diferente das imagens tradicionais." (FLUSSER, 2011, p. 23)

${ }^{5} \mathrm{~A}$ fotografia foi objeto de pesquisas e estudos de vários contemporâneos e sua invenção não se deu a partir de uma única pessoa. Pesquisadores como o britânico William Fox Talbot, o francês Hippolyte Bayard e o também francês radicado no Brasil, Hércules Florence, são alguns dos que, de alguma forma contribuíram com a invenção e o aperfeiçoamento da fotografia em seu início, porém, a invenção oficial na forma do Daguerreótipo, é creditada ao francês Louis Jacques Mandé Daguerre, que seguiu aperfeiçoando o trabalho de seu falecido sócio Joseph Nicéphore Niépce, a quem é atribuída a autoria da primeira fotografia oficial (1826), uma imagem em preto e branco, fixada em uma placa de estanho coberta com betume da Judeia, um derivado fotossensível do petróleo, mostrava a vista da janela da casa de campo de sua família, em Viviers-le-Gras (nordeste da França).
} 
devido "a esse princípio de realidade próprio à relação da imagem fotoquímica com seu referente" (Dubois, 2012, p. 26), já no seu primeiro século de existência, a imagem fotográfica pôde alcançar o papel de documento e a característica de "espelho do real". Nesse contexto, a invenção da fotografia, acabou "permitindo que a arte rompesse seu compromisso com a verossimilhança, ao concentrar-se, não na representação, mas nos meios expressivos" (FABRIS, 2006, p.159), com isso, vimos brotar novas possibilidades imagéticas, desde a pintura, desenho, a própria fotografia, uma dimensão que nos guiou além da figuratividade pictórica, abrindo ainda mais caminhos para as subjetividades e suas expressões, imagens e imaginários.

Desde a sua publicização (1839), a fotografia sempre provocou profundos debates e reflexões a respeito de si mesma e das imagens como um todo, "situada que estava na encruzilhada de "três polos de interesses contraditórios": as belas-artes, as ciências e a indústria" (SAMAIN, 2006).

Para Flusser (2011), já tratando, aqui da fotografia em um contexto sociopolíticoeconômico e cultural, diferente da fotografia em seu nascimento (fins do século XIX início do século $X X)$, mais especificamente, meados da década de oitenta do século $X X$, "todo ato cientifico, artístico e político visa eternizar-se em imagem técnica, visa ser fotografado, filmado, videoteipado" (FLUSSER, 2011, p. 29), de modo que, "o gesto fotográfico desmente todo realismo e idealismo. As novas situações se tornarão reais quando aparecerem na fotografia. Antes, não passam de virtualidades" (FLUSSER, 2011, p. 47). Isso, nos leva a pensar sobre o contexto atual da produção, uso e distribuição de imagens por toda a internet, a atual compulsão em produzir imagens técnicas, sejam através de celulares, câmeras fotográficas mais sofiticadas, webcam e tantos outros aparelhos e máquinas, e de pronto ou instantaneamente publicá-las em redes sociais por toda a internet, como se não existíssemos, caso, lá não estejamos, nós ou qualquer de nossas imagens, como dito acima, Narcisos entorpecidos por nosso próprio eidôlon, condenados ao ritual de iteração de Sísifo. De forma que, a fotografia digital, passa a ser a realidade, Flusser, afirma, ainda, "tal inversão do vetor da significação caracteriza o mundo pós-industrial, todo funcionamento " (FLUSSER, 2011, p. 47). O significante é a realidade e não o significado ${ }^{6}$. A imagem, as imagens das imagens, passam a ocupar o lugar ou a

\footnotetext{
${ }^{6}$ De forma geral, pefiro a versão da semiótica peirceana ao invés da dicotomia da semiologia, assim, substituiria "significante" por "signo" ou "representâmen" e "significado" por "objeto", ainda assim faltaria tratar do "interpretante", como esse não é o objetivo principal do texto, mantive os termos utilizados por Flusser.
} 
importância dos corpos. Flusser, adverte-nos sobre as mudanças ocorridas em uma possível sociedade da informação e um "imperialismo pós-industrial",

Quem possui o aparelho não exerce o poder, mas quem o programa e quem realiza o programa. O jogo com símbolos passa a ser jogo do poder. Trata-se, porém, de jogo hierarquicamente estruturado. $O$ fotógrafo exerce poder sobre quem vê suas fotografias, programando os receptores. O aparelho fotográfico exerce poder sobre o fotógrafo. A indústria fotográfica exerce poder sobre o aparelho. E assim ad infinitum. No jogo simbólico do poder, este dilui e se desumaniza. Eis o que seja "sociedade informática e "imperialismo pós-industrial". (FLUSSER, 2011, p. 41)

Tais afirmações e a constatação das mesmas em nossa sociedade contemporânea, levanta algumas questões; quem ou quê, programa?; quem ou o quê, realiza o programa?; quais as intenções do programa? Para Huchet, no que tange as imagens digitais,

A imagem numérica, assim, é uma "húbris" que já não trabalha com e sobre fragmentos do real (como o fazia a colagem), mas sobre os bits ou unidades genéticas do sentido, que são as do programa informático, construídas a partir de modelos lógicos e matemáticos que constituem eles próprios interpretações formalizadas do real. (HUCHET, 2006, p. 291.)

Vale também questionarmos, mesmo que sem respostas imediatas; que ideologias regem as interpretações do real, por tais modelos lógicos e matemáticos, citados por Huchet (2006)?; que tipo de sociedade vivemos, a sociedade da imagem ou da matemática e seus algoritmos computacionais, já que a parte visível das imagens, apenas se dá por conta de longos textos numéricos?; ou refletirmos sobre tais coisas, seria apenas uma redundância do pensar a atual sociedade da informação?

Levando em conta a massificação não apenas do consumo, e também da produção dessas mesmas imagens, que aparentemente se torna cada vez mais fácil e dispensa conhecimentos técnicos específicos, já que algum sistema informático ou computacional, estará aposto e munido de um potente hardware não apenas para capturar os raios luminosos refletidos dos objetos, mas também processá-los e transformá-los de sinais analógicos para digitais, automaticamente (como acontece com a fotografia digital), mesmo que seu operador não tenha os devidos conhecimentos, fica a cada dia mais difícil entender ou separar o que é o "Operator" e o "Spectator", segundo a ótica de Barthes (2015). Logo, todos observam e são observados, por mais que não estejam dotados de conhecimentos ou vivências que 
possibilitem decifrar as mais profundas camadas de leituras das imagens, assim também serão influenciados, por mais que não tenham consciência.

Parecemos assistir a uma espécie de volta ao "Renascentismo", ao determos nossos olhares as mesmas imagens citadas acima, é fácil perceber uma exaltação a figura humana e não somente a sua imagem, mas a tudo que das mentes e mãos dos seres humanos pode brotar. Poderia se afirmar que vivemos um possível "antropocentrismo imagético", mediado pela tecnologia, que não deixa de ser uma produção humana. Ao observar uma simples foto de pôr do sol, postada no Instagram, a depender da legenda que a acompanha, podemos ser levados a interpretar aquilo, como uma exaltação a natureza, seu belo, sublime..., porém, talvez, se nos determos em uma análise mais profunda e segundo tudo discutido acima, tal imagem do pôr do sol, mesmo sem ter ali presente a presença imagética-objetiva do sujeito que a produziu, signifique apenas uma tentativa narcisista de afirmar ou mesmo reafirmar, uma imagem da imagem idealizada pelo sujeito que a produziu, e assim deseja fixar em mentes outras. Assumo que tais suposições, carecem de pesquisas concretas, mas penso que ao menos já é válido um pensamento que gere tais reflexões.

A ideia de um possível "antropocentrismo imagético" mediado por tecnologias, à primeira vista, parece algo sedutor e lógico, já que as mesmas tecnologias, são frutos do ser humano e a maioria das imagens atuais, como dito acima, parecem exaltar tudo que é humano. Porém, volto a citar a importância de pensarmos sobre o papel da tecnologia na atual sociedade, quais caminhos ela está nos levando e quais ideologias podem estar regendo isso tudo. Ao que tudo indica, há uma linha tênue, entre um possível "antropocentrismo imagético", e um "tecnocentrismo imagético" e virtual. De modo que, a única certeza que temos, é que todas as possibilidades tecnológicas e imagéticas só foram possíveis com o advento e a invenção da fotografia, que serviu como modelo de aparelho não apenas imagético para atual sociedade e toda sua tecnologia. Por conta disso, a necessidade de se pensar o ato fotográfico e tudo que o rodeia, nunca terá fim.

\section{Considerações finais}

Ao que tudo indica, da pré-história aos dias atuais, não somente os modos de produzir imagens mudaram, se transformaram ou foram simplesmente acrescidos por novos métodos e técnicas; do desenho à pintura e escultura, da fotografia fotoquímica à fotografia digital e as várias imagens derivadas dos computadores e seus softwares. $O$ 
homem, seja por um "narcisismo ingênuo" ou por qualquer outra necessidade, parece haver passado de senhor, à escravo das imagens, não mais se servindo das mesmas para se situar no mundo, se guiar e de alguma maneira passa a viver em função das imagens, nesse contexto, a fotografia digital e toda sua virtualidade, exerce grande influência. De modo que poderiamos afirmar: fotografamos, postamos, logo, existimos. As imagens parecem validar não apenas as experiências humanas mais fúteis, como idas a shows, jantares em familia, mas além disso, aliadas ao poder feroz e veloz da internet, parecem ter o poder de validar e afirmar a própria existência humana, de forma instantânea e muitas vezes efêmera.

\section{Referências}

ALBERTI, Leon Battista. Da pintura / Leon Battista Alberti; tradução Antônio da Silveira Mendonça. $2^{\circ}$ ed. Campinas: Editora da Unicamp, 1999.

BARTHES, Roland. A câmara clara: nota sobre a fotografia. Tradução de Júlio Castañon Guimarães. Edição especial. Rio de Janeiro: Nova Fronteira, 2015. (Coleção 50 anos).

BELTING, Hans. Sísifo ou Prometeu? Da arte e da tecnologia, hoje. Tradução de A. Morão, edição; J. F. Figueira e V. Silva. Lisboa: KKYM + IHA, 2014.

DEBRAY, Régis. Vida y muerte de la imagen: historia de la mirada en occidente. Barcelona: Paidós, 1994.

DUBOIS, Philippe. 0 ato fotográfico e outros ensaios. 14. ed. Campinas: Papirus, 2012. (Série Oficio de Arte e Forma)

FABRIS, Annateresa. A imagem técnica: do fotográfico ao virtual. In: FABRIS, Annateresa; KERN, Maria Lúcia Bastos (Orgs.). Imagem e conhecimento. São Paulo: Edusp, 2006. p. 157-178.

FLUSSER, Vilém. Filosofia da caixa preta: ensaios para uma futura filosofia da fotografia. São Paulo: Annablume, 2011.

HUCHET, Stéphane. A nova Górgona ou o céu do processo. In: FABRIS, Annateresa; KERN, Maria Lúcia Bastos (Orgs.). Imagem e conhecimento. São Paulo: Edusp, 2006. p. 287-304.

JOLY, Martine. Introdução à análise da imagem. Lisboa, Ed.70, 2007. 
KERN, Maria Lúcia Bastos. Imagem Manual: pintura e conhecimento. In: FABRIS, Annateresa; KERN, Maria Lúcia Bastos (Orgs.). Imagem e conhecimento. São Paulo: Edusp, 2006. p. 15-29.

ROCHA, Rose de Melo. Morin e Flusser: a teoria da imagem como aventura antropológica e matemática imaginária. Galáxia, São Paulo, v. 13, n. 25, p. 74-84, Junho 2013. Disponível em:

$<$ http://www.scielo.br/scielo.php?script=sci_arttext\&pid=S1982-

$25532013000200007 \&$ Ing=en\&nrm=iso>. Acessado em 23 de setembro. 2017.

Disponivel em: <http://dx.doi.org/10.1590/S1982-25532013000200007>. Acesso em:

ROUILLĖ, André. A fotografia: entre documento e arte contemporânea. São Paulo:

Editora Senac, 2009.

SAMAIN, Étienne. Quando a fotografia (já) fazia os antropólogos sonharem: O Jornal La Lumière (1851 - 1860). In: FABRIS, Annateresa; KERN, Maria Lúcia Bastos

(Orgs.). Imagem e Conhecimento. São Paulo: Edusp, 2006. p. 193-227.

SANTAELLA, Lucia. Imagem: cognição, semiótica, mídia. Lucia Santaella, Winfried North. São Paulo: lluminuras, 1997, 2015.

SANTAELLA, Lucia. Leitura de imagens. Lucia Santaella. São Paulo: Editora Melhoramentos, 2012. (Como eu ensino).

UBINHA, Paulo de Tarso. CASSORLA, R.M.S. Narciso: polimorfismo das versões e interpretações psicanalíticas do mito. Rev. Estudos de Psicologia, Campinas, v. 20, n. 3, p. 69-81, set./dez., 2003. 